\title{
A STUDY ON QUALITY OF LIFE OF MIDDLE-INCOME GROUP ALONG URBAN CANAL WATERFRONTS
}

With special reference to Greater Colombo region

\author{
MADHUSHAN A.M.L. ${ }^{1} \&$ DHARMASENA J. ${ }^{2}$ \\ 1, 2University of Moratuwa, Katubedda, Sri Lanka \\ ${ }^{1}$ vienterinne@gmail.com, 2janakahedh@gmail.com
}

\begin{abstract}
In most of the cases, canal network in Greater Colombo region work as the drainage system of the urban area and as the backyard of the city. Therefore, there is a lack of attention to the canal waterfronts by the government and by the public. Hence, this research was to find out and evaluate the factors, which will affect the quality of life of people along urban canal waterfronts. It has been discussed in terms of liveability through a series of carefully selected indicators. Liveability surveys were conducted along five canal waterfronts and the participants' perceptions were taken. Every canal waterfront was assigned a rating of over 25 qualitative and quantitative factors (set of indicators) across six broad categories (dimensions): safety, comfort, health and wellbeing, mobility, environment, and sociocultural factors. Each qualitative factor was given a rating from 1(tolerable)-5(intolerable). Qualitative factors were then combined with quantitative factors through a series of equations to form the liveability index. According to the proposed liveability index, transport dimension index is ideal (100), while the health and well-being dimension is the lowest (27). This will help for the creation of government policies, plans, rules and regulations and when implementing projects along urban canal waterfronts.
\end{abstract}

Keywords: Canal waterfronts, Quality of life, Liveability

\section{Introduction}

Water has been a prominent feature that was attached to human being from ancient time. There is a known history of starting of civilizations associated with rivers. Nile valley civilization, Indus valley civilization, Huang ho civilization are some of the examples. Civilizations had been originated by the settling of the built environment beside rivers, mainly due to the agricultural needs, as well as for the ease of transportation and due to the day-to-day needs. It will show the connection that had prevailed between water and human being over a long period. In most of the cases, the best cities have evolved with the existence of a waterbody. That is because of the evolution of the same context originated at ancient time. "If a city possesses a water resource in a kind of lake a river, a canal etc. .... it has a great influence on enhancing the "quality" of the city while giving it an "identity". But unfortunately our town planners and city builders have not properly understood or identified the potential. As a result of that, although most of cities have some water bodies it mainly is being used as the part of drainage network or the back yard of city" (Herath, 1996).

Fortunately, Urban Development Authority of Sri Lanka has taken steps recently to develop the Colombo city by addressing the canal system and the waterbodies under the concept "Aquarina". This will take a new step in the development of the built environment and the quality of life of people along waterfronts in the near future. The projects that have been undertaken for the development of cities based on canal systems show how the other countries have used the waterways in an effective way. In addition, it shows how they have used those in case of recreation and for the improvement of the quality of life. 
In most of the cases within the Colombo context, canal network works as the drainage system of the urban area also as the backyard of the city. Therefore, there is a lack of attention to the canal waterfronts by the public and the government. On the other hand, it directly affects the quality of life of people in those neighbourhoods. There is a gap of research in the particular field too. Therefore, this research was conducted to find out and evaluate the factors, which affect the quality of life of people along urban canal waterfronts.

The study will help in providing information for the creation of government policies, plans, rules and regulations by the respective authorities. In addition, the results can be used as a design tool in implementing community-based development projects along canal banks and in their neighbourhoods. In addition, the study outcome will provide an idea about the liveablity status along urban canal waterfronts within Greater Colombo region. In addition, the outcome can be used to compare the status of quality of life of people along canal waterfronts worldwide.

\section{Literature Review}

This section contains two sub sections reviewing the two topics urban canal waterfronts and the quality of life.

\subsection{URBAN CANAL WATERFRONTS}

Urban canal waterfronts have become much popular among city planners, urban designers, architects and landscape architects to address the issues of the increment of population density and urban sprawl, and to provide them with recreational facilities. This section reviews the evolution of canals, canal and waterfront definitions and their importance, related socio- cultural, religious and traditional aspects/ rituals, and the modern lifestyle in urban canal waterfronts.

\subsubsection{Evolution of canals}

The first civilizations were formed in association with water and they settled along river valleys. There were four main river valley civilizations, namely Mesopotamian civilization, Nile river valley civilization, Mohenjo Daro, Harappa, and Chinese civilization on the Yellow river. Canals were first constructed during the Mesopotamian civilization to control the water of Euphrates and Tigris rivers and to direct it to their cultivation lands. The Suez Canal, connecting the Nile and Red Sea was constructed by the Persian emperor within the era $520 \mathrm{BC}$ to $510 \mathrm{BC}$. Evidence also suggest that canal waterways were built by the Egyptian Pharaoh civilization to transport granite (Lalor, Wolowski, \& Roscher, 2015). The Chinese were the greatest early builders involved in constructing canals ( $3^{\text {rd }}$ century BC and onwards) to carry water into their irrigation lands and as a transportation media. Many of the European canals were constructed within $12^{\text {th }}$ to $1^{\text {th }}$ century. Two famous examples are Giethoorn in Netherlands (a world heritage site) and Venice in Italy (Floating City/ City of Canal). In the present world, Panama Canal (82km), Panama, Suez Canal (193.3km), Egypt, and the Kiel Canal $(98 \mathrm{~km})$, Germany are named as the three great canals in the world (Encyclopedia Britannica). Apart from them there are many famous canals and canal waterfronts in the world, which include, Grand Canal, China, Dutch Canal, Netherlands, Bruges Canal, Belgium, Annecy Canal, France, etc. The canals and canal waterfronts have been identified by landscape architects and town planners as having a unique character which can be used to maximize the imageability of the city. Unfortunately, some countries in the world do not pay much attention towards canals which has resulted in canals being garbage disposal sites in some areas.

Sri Lankan history of canals (referred to as "Ela" in Sinhala language), is boned with irrigation and dates back to the period of King Pandukabaya (474 BC - 367 BC). Sri Lankans were the first to build large reservoirs and a network of irrigation schemes to provide water for the large expanses of agricultural lands. In addition to agricultural purposes, kings built canals (motes) to protect their kingdoms/ palaces from invaders. Constructed by King Dathusena (455 AD - 473 AD), Yoda Ela (Jaya Ganga), bringing excess water from Thisa wewa (tank) to Kala wewa in Anuradhapura can be considered as an amazing creation built with a much greater technology when considering the modern methods. Minipe Ela, built by King Aggabhodhi 1 (564 AD- 594 AD) to transport water from Mahaweli river to agricultural lands is also a famous historical canal. King Veera Parakramabahu VIII (1477-1496) of the Kotte kingdom built a network of canals covering Colombo and the nearby villages to transport produce such as arecanuts, cloves, cardamom, pepper and cinnamon to Negombo seaport easily. This canal network was renovated and modified by the Portuguese, Dutch and by the British within their ruling periods. The primary objectives of constructing canals (irrigation, navigation, conveyance of flood water etc.) have been ignored in urban 
areas with time and due to other technological innovations. This is mainly due to the lack of attention towards the canal network by the government and the local community. One main objective of utilizing canals nowadays is to remove excess flood water, sewage, and industrial waste from the much congested urban region to nearby lakes, rivers, bogs, marshlands and to the sea.

\subsubsection{Canal and waterfront definitions and their importance}

The word "canal" was derived from the Old French word Chanel, which means "channel." According to National Oceanic and Atmospheric Administration/NOAA (2018), a canal is a manmade waterway that allows boats and ships to pass from one body of water to another. According to Anupoju (n.d.), a canal is an artificial channel constructed to convey water from rivers, reservoirs, etc. for several purposes like power generation, navigation, irrigation, etc. Waterfronts have been defined as "The part of a town or city adjoining a river, lake, harbour, etc." in the Oxford American Dictionary. Giovinazzi \& Moretti (2010) has defined the term waterfront as "The urban area in direct contact with water". The canals were used only in agricultural activities, feeding for domestic animals and for some other human purposes by the ancestors in the 4 great river valley civilizations. Then with time, canals were used for many other activities with the evolution of human being. Latterly, canals were constructed for navigation (as a route for boats, barges, sometimes for ships), Irrigation, drinking water, hydroelectric power, and to convey excess amount of water from a river during floods. In addition, canals have advantages in military activities and in the protection of special places like ports, palaces, parliaments etc.

\subsubsection{Socio-cultural, religious and traditional aspects and rituals related to canals and canal waterfronts}

There are many important aspects related to canals since canals have been boned with agriculture from the ancient time. In addition, the ancestors devoted water to the god and sometimes they worshiped it as a sacred element. Many of the humans are considering water as a sign of purity or as an auspicious element in the modern society too. As we all know, every religion gives priority for water. From previous literature, it is clear that every religion is been bonded with water however. According to Oestigaard \& Firew (2013), still the Ethiopian Christians are practicing water based religious rituals along the Nile River. According to Sharma (2003), Water is a multifaceted symbol in Hinduism. Along with earth, fire, air, and space, it is regarded as one of the 'pancha-tatva', five primeval elements of the universe. Water as a particular element with associated characteristics and related symbolism forms the basis of the texts of the Jyotish Shastra (Hindu astrology) and the Ayurveda (ancient Hindu medicine). Buddhism has also given priority for water, which is bonded with the religion. Sri Lanka, India, Nepal, China, Japan are the best countries that practice this religion and its water related rituals.

Apart from religious activities, canals have been bonded with irrigation activities from the ancient time. Canal, Irrigation activities and the religion combines to create traditional activities and the functions along canal waterfronts. According to Oestigaard (2005), all religions do rituals related to water. In addition, about 50-70 million of Hindus in India gather for a single purpose to rivers and canals to clean with holy water and they believe that their sins will be erased with this holy water. Still Hindus and Buddhist practice the floating of ashes of dead bodies in canals and the rivers. Christians in Asian and European countries have a traditional practice of by hearting a wish on their mind, lighting a coconut oil lamp, and floating it on a canal or a river. Floating markets and associated tourism is also one of main upcoming traditional trend in the world right now.

\subsubsection{Modern lifestyle}

Modern lifestyle along urban canal waterfronts differs from place to place. It varies from lower income group to higher income group according to the place where the canal is located, according to the water quality, recreation effect etc. The canals in some countries are being used as a landmark for increasing the value of land plots around the waterfront. Luxury apartments and hotels have been constructed beside canals and they have been used as tourist destinations. In addition, there is a negative side too. Low-income people create shanty houses along urban canal waterfronts and these places have become a garbage dump and also as their backyards. Canal Oriented Developments (COD) are also taking place in many locations of the world to improve the quality of life of the community within the particular context. Nowadays, the urban community do not have the capacity to relax with nature due to the higher density of buildings in urban areas. Therefore, these people are more interested in the topic of Public Open Recreational space (PORS), in the urban context. People do many researches on PORS in urban context to cater for such 
communities. Therefore, the trend in the classical world is to make the waterfronts to recreational spaces, public parks, jogging tracks etc.

\subsection{QUALITY OF LIFE}

Economists, Social scientists, and various researchers have taken attempts to give a direct definition to the quality of life. However, it is a bit difficult task to provide a direct definition to the quality of life since various people feel it in their own perception. Quality of life has been defined by various researchers, journal and article publishers in their own way as follows. According to Oxford American Dictionary, the quality of life means "the standard of health, comfort, and happiness experienced by an individual or group". According to Cummins, Eckersley, Pallant, Vugt, and Misajon (2003), the term quality of life is measured in terms of economic statistics in the latter half of $19^{\text {th }}$ century. "The quality of life of any individual or community can in a direct and simple way be related to income" But this argument is having a lack in definition with some of parameters like health, comfort, personal perception in happiness etc. Carmichael, Gleason, Lehrmitt, \& Luppino (2007) state that the researchers around 1930 defined the quality of life in terms of Gross Domestic Products (GDP) and it was used as an economic indicator. However, in around 1960 the researchers have identified that this is only a measure of the income of a nation and not the quality of life or the well-being of people. According to Carmichael, Gleason, Lehrmitt, \& Luppino (2007), the term quality of life is much more complex to define and it is a multifaceted concept since it incorporates qualitative indicators such as level of satisfaction and happiness. By the time, experts began to consider the air quality to be affected for the quality of life too. This idea influenced into researchers and they have defined that the quality of life does not only depend on the social and economic measures but also with the environmental factors such as air quality, street cleanliness. From above definitions, it can be concluded that the quality of life is affected by many factors such as physical, mental, social, economic, cultural, etc. Therefore, we can understand that it is a hard task to give a definition for such a phrase. A set of dimensions and indicators for measuring the quality of life of people along canal waterfronts have been taken in this study by referring to literature carefully.

\subsubsection{Sustainability}

According to the Oxford dictionary, the term Sustainability is "the ability to be maintained at a certain rate or level". Aalfs, et al. (1998), have agreed that sustainability "is a process of continually improving the way we live in order to respect the reality of limits, whether those limits are imposed by nature or embraced voluntarily by people living together in cooperation". Hart (2006) states, "Sustainability is related to the quality of life in a community, whether the economic, social and environmental systems that make up the community are providing a healthy, productive, meaningful life for all community residents, present and future". According to the above definitions, it can be concluded that the quality of life of people could be in a higher level if the particular community is in a sustainable stage.

\subsubsection{Liveability}

Liveability is also a parameter that always bonds with the quality of life. This factor is often talked in the world when referring to the most liveable cities. A liveability survey is carried out in most cities around the world to know up to what extent the city is liveable and the outcome will be given through a liveability index. Researchers including Wheeler (2001), Balsas (2004), and Heylen (2006) had stated that the liveability is a difficult term to define and to measure. Liveability is the living condition of a place and the user perception on the particular place while the terms like "quality of life", "well-being" and "life satisfaction" are in the same conceptual frame of liveability (Lyndhurst, 2004). According to Cambridge English dictionary, liveablity is "the degree to which a place is suitable or good for living in". That is simply the ability to live within a particular area. According to Shamsuddin, Hassan \& Bilyamin (2012), "Liveability is a concept that has been practiced worldwide. It is equivalent to the quality of living in a city and is determined by many elements". they also state that walkability is one of the main parameters to achieve the urban liveability. The factors that are affecting the liveability in the perspective of Landscape Architecture which are directly influencing the quality of life are been discussed under the theoretical framework.

\subsubsection{Liveability indices, general construction of a liveability index and indicators}

Liveability indices are used to evaluate the progress in achieving socio cultural, economic and environmental targets within a geographical region and to communicate their state of quality of life. 
Communities measure the corresponding progress by using a carefully selected set of indicators. A livability index is "something other than the gathering of indicators; it aims at providing a direct contribution to policy intervention" (Hortulanus, 1999). A liveability index is a tool that communicates and exhibits the improvement of a given aspect in the society, and which distinguishes problematic areas. The best way of ranking the most liveable cities in world is been done by The Economist Intelligence Unit (The EIU). It gives an annual outcome in the form of The Global Liveability Index. Liveability indices provide necessary information for policy makers to create policies accordingly and the administrators to take care about the neglected aspects. It is a measure of quality of life within a given context.

\subsubsection{General construction of a liveability index and indicators}

According to Carmichael, Gleason, Lehrmitt, \& Luppino (2007), "The purpose of an index is to communicate data in such a way that it encourages the government to implement appropriate legislation" That is same as explained in the last section. They also state that, the first step of creating an index is the identification and the analysis of the demographics of the community. This can be done by conducting a pilot survey where the targeting community is. Then the researcher must be able to create a carefully selected set of indicators. Those factors must be in a level of understandable format of the quality of life. A set of indicators are the final understandable outcome of a good review on literature. This must be selected precisely by the researcher since it will be the summery of the overall presentation of the liveability survey. Sometimes the set of indicators are also known as 'Dimensions' by various researchers. Also, sometimes researchers have categorized a set of indicators under each dimension. According to EIU liveability survey, they have categorized comfort over 30 quantitative and qualitative factors across five broad categorize. These 30 factors will be the set of indicators. A better indicator must represent both desirable and measurable outcomes. The creators of indicators must have an ability to simplify a set of complex data into simple format and to provide a clear perspective of a bigger picture.

\subsubsection{Income group classification}

The World Bank has divided the world's economies into 4 main income groups: High-income group, Upper middle-income group, Lower middle-income group, Low-income group. It is based on a measure of national annual income per person, also known as GNI (Gross National Income) per capita, calculated using the Atlas method. According to the above classification method, Sri Lanka falls under the lower-middle income group. The GNI per capita of Sri Lanka has increased until 2019 and now it has been dropped again in 2020. Sri Lanka once reached the upper-middle income group in 2017 and 2018 with a GNI per capita just above $4050 \$$. Sri Lanka is in the margin of lower-income group and the middle-income group. Therefore, there is a huge possibility in the fluctuation of country's economic status within these two margins. According to the global classification data, the average national monthly income rate of a person in Sri Lanka is around 57300lkr in 2019.

M onthly income of a person $=($ GNI per capita) $\mathrm{x}$ (Average US $\$$ Exchange rate)

12

Therefore, the lower margin of the income level of upper middle-income group of Sri Lanka can be categorized nearly within that income range.

\section{Theoretical Framework}

Selection of the set of indicators must be done preciously in order to have a valuable outcome from the community. It was done by analyzing the literature and theories. Also, these kinds of researches are mainly focusing on the user perception of the targeting group. The following two theories were taken in order to build up the foundation for the selection of indicators and to inquire the user perceptions.

- Cognitive theory - study on the three factors environmental, behavioral, and personal.

- Probing theory - inquiring closely into something; searching. This can be a study on physical exploring and examine.

\subsection{CRITERIA FOR THE SELECTION OF INDICATORS}

A set of dimensions were selected in seven broad categories and over 25 subcategories according to the definitions provided by various researchers, planners, designers, institutes/units, or teams who are responsible for the formulation of the liveability index. Furthermore, these were divided into quantitative 


\begin{tabular}{|c|c|c|c|c|c|}
\hline $\begin{array}{l}\text { Source } \\
\text { Dimension }\end{array}$ & $\begin{array}{c}\text { VanZerr } \\
\text { \& Seskin } \\
(2005)\end{array}$ & $\begin{array}{c}\text { Carmichael } \\
\text { et al. } \\
\text { (2007) }\end{array}$ & $\begin{array}{l}\text { Fatemi and } \\
\text { Islam (2014) }\end{array}$ & $\begin{array}{l}\text { Lagas et al. } \\
\text { (2015) }\end{array}$ & $\begin{array}{l}\text { The Global } \\
\text { liveability } \\
\text { index (2019) }\end{array}$ \\
\hline $\begin{array}{l}\text { Healthcare / Health and } \\
\text { Well-being }\end{array}$ & $\sqrt{ }$ & $\sqrt{ }$ & $\sqrt{ }$ & $\sqrt{ }$ & $\sqrt{ }$ \\
\hline Education & $\sqrt{ }$ & $\sqrt{ }$ & $\sqrt{ }$ & $\sqrt{V}$ & $\sqrt{ }$ \\
\hline Cultural dimension & $\sqrt{ }$ & $\checkmark$ & $\checkmark$ & X & $\sqrt{ }$ \\
\hline Social dimension & $\sqrt{ }$ & $\sqrt{ }$ & $\sqrt{ }$ & $\sqrt{ }$ & $\sqrt{ }$ \\
\hline Environmental dimension & $\sqrt{ }$ & $\sqrt{ }$ & $\checkmark$ & $\sqrt{ }$ & $\sqrt{ }$ \\
\hline $\begin{array}{l}\text { Transport/ Mobility/ } \\
\text { Accessibility }\end{array}$ & $\sqrt{ }$ & X & $\sqrt{ }$ & $\sqrt{ }$ & $\boldsymbol{V}$ \\
\hline Infrastructure & X & $\sqrt{ }$ & $\sqrt{V}$ & $x$ & $\checkmark$ \\
\hline Economy & $\sqrt{ }$ & $\sqrt{ }$ & $\mathscr{L}$ & x & $\sqrt{ }$ \\
\hline Housing & $\sqrt{ }$ & X & $x$ & $\sqrt{ }$ & $x$ \\
\hline Safety & $\sqrt{ }$ & $\sqrt{ }$ & $V$ & $\sqrt{ }$ & $\sqrt{ }$ \\
\hline Comfort & $\sqrt{ }$ & $y$ & 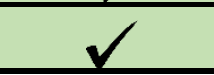 & $x$ & $\sqrt{ }$ \\
\hline
\end{tabular}

and qualitative factors under each category. Following table, represent a summary of an overall review on five literary sources.

Table 1: Summary of an overall review on five literary sources

(Source: Author)

\subsection{SELECTED SET OF DIMENSIONS AND INDICATORS}

These set of indicators are the parameters that were taken by referring to the literature, to assess the quality of life of people along canal waterfronts in greater Colombo region in this study. The qualitative factors were measured by conducting a liveability survey through a questionnaire at each of the five case study locations. After that, the perceptions were rated to convert those into a set of countable and representative data.

\begin{tabular}{rll}
\hline $\begin{array}{r}\text { Liveability } \\
\text { Dimension }\end{array}$ & \multicolumn{1}{c}{ Qualitative } & \multicolumn{1}{c}{ Quantitative } \\
\cline { 2 - 3 } Safety & $\begin{array}{l}\text { Feeling of safety at residential level, } \\
\text { In the neighbourhood, Night lighting }\end{array}$ & No. of crimes \\
\hline Comfort & $\begin{array}{l}\text { Noise, Odor tolerability, Visual } \\
\text { comfort, Mental comfort, Thermal } \\
\text { comfort }\end{array}$ & $\begin{array}{l}\text { Visibility, Thermal comfort in terms } \\
\text { of Temperature and Wind }\end{array}$ \\
\hline Health and & $\begin{array}{l}\text { Satisfaction level of Sanitation } \\
\text { facilities }\end{array}$ & $\begin{array}{l}\text { Spread of diseases related to water } \\
\text { along canal waterfronts }\end{array}$ \\
\hline Socio-Cultural & $\begin{array}{l}\text { Opportunity for social interaction, } \\
\text { Sttitude toward the development of } \\
\text { Tourism }\end{array}$ & Availability of open spaces \\
\hline Mobility and & $\begin{array}{l}\text { Attitude regarding water based } \\
\text { transportation, and connectivity }\end{array}$ & $\begin{array}{l}\text { Connectivity (footpaths/road } \\
\text { network), Accessibility - Access to } \\
\text { main roads/ disable accesses }\end{array}$ \\
\hline Environment & $\begin{array}{l}\text { Satisfaction level of; environmental } \\
\text { quality, views and vistas along the } \\
\text { canal, Open spaces requirement }\end{array}$ & Water quality, Air quality, Rainfall \\
\hline
\end{tabular}

Table 2: Selected set of dimensions and indicators

(Source: Author) 


\section{Methodology}

The following figure shows the methodological structure that was used for this particular study.

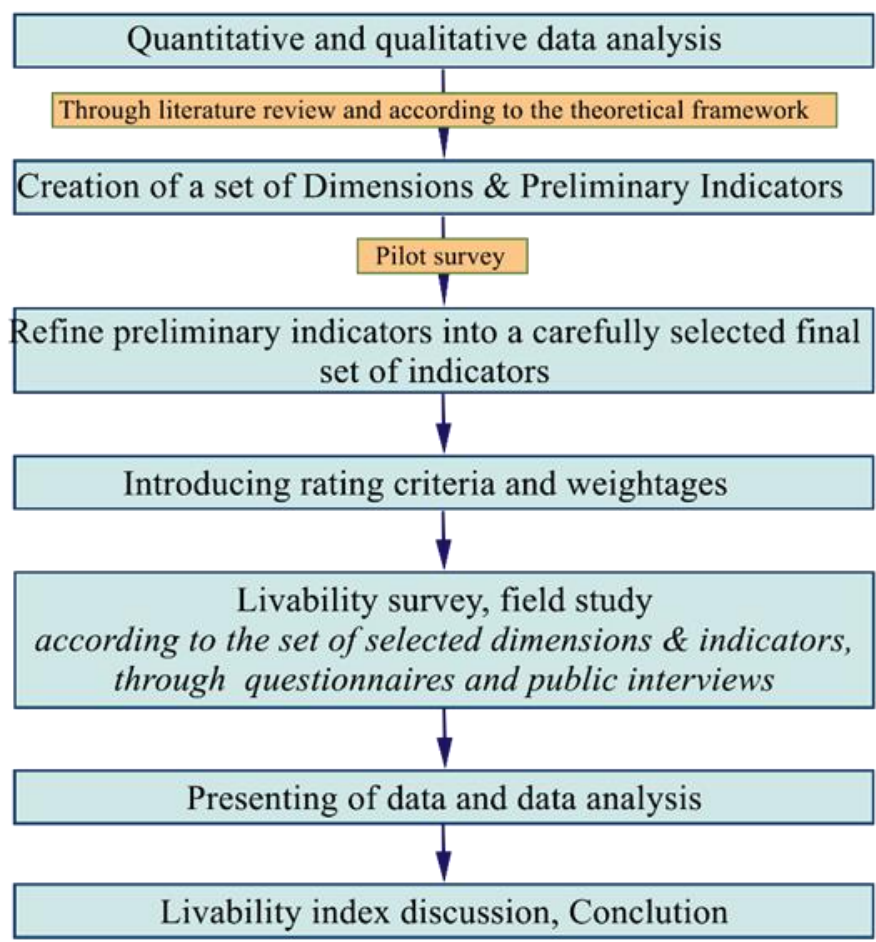

Figure 1: Methodology structure

(Source: Author)

\subsection{CASE/ SAMPLE SELECTION CRITERIA}

The Greater Colombo region was considered for this study because it consists of a massive network of waterbodies such as canals, wetlands, lakes, rivers, and the sea front. This research only focuses on canals due to the massive network of them all around Colombo region (in total $43 \mathrm{~km}$ long canal network: according to Colombo gazette website), and due to the immerging of some physical and social problems along those. The targeting community for this research will be the middle-income group. The selection of only this group is because, the higher-income communities won't get much influenced by the condition of canal waterfronts, as they will be mostly within their own luxury premises and the lower-income communities will not care of the environmental condition as long as they get a place to live. Therefore, the middle-income community can be considered as the most affected by the canal waterfronts, and thereby the most suitable for this study.

The case study areas were selected to have a coverage of the entire canal network in Greater Colombo region. Three main canal waterfronts were selected for the case study namely, Kirulapone canal, Kinda canal, and Dematagoda canal. In addition, there are two comparative sub locations within two of the selected canals to have a better comparison than selecting a one single location. Six individuals were taken from each sub location and altogether the sample consisted of 30 participants. The six samples were taken within a distance of approximately $100 \mathrm{~m}-200 \mathrm{~m}$ along the canal waterfront in each single sub location. The study was limited within few aspects. The number of participants were limited due to the Covid-19 pandemic situation and the middle-income group was selected through a comparative observation, of the physical character of people and their shelter

\subsection{QUESTIONNAIRE}

The main method used for the collection of data was the questionnaire. The questionnaire is to assess the quality of life of middle-income group (qualitatively) along urban canal waterfronts within Greater Colombo region. The questionnaire is focusing on the user perception on their quality of life along the canal waterfront and the nearby surrounding. Every sub location is assigned a rating across six broad categories 
(Dimensions): Safety, comfort, health and wellbeing, social interaction, mobility and environment. These have been further categorized into subcategories (Indicators) to increase the accuracy. The questionnaire was prepared by including 15 questions under these subcategories. The main objective of the questionnaire is to analyse the qualitative data. The above-mentioned questions are assigned with a rating of 1-5 where 1 is considered as tolerable and 5 is considered as intolerable or sometimes 1 is considered as the negative side and 5 is considered as the positive side. Simply according to a Likert scale.

\section{Research Findings and Discussion}

This section consists of a general discussion about the liveability survey followed by the proposed liveability index for greater Colombo canal waterfronts. The proposed liveability index is first presented for the qualitative dimensions representing only the human perception on the liveability of canal waterfronts. The qualitative dimensions are then represented in combination with quantitative dimensions to give the most accurate outcome.

\subsection{ABOUT THE LIVEABILITY SURVEY}

This liveability survey was conducted to identify the existing condition of the quality of life of middleincome group and this will be helpful in the identification of shortcomings in future projects along canal waterfronts and the nearby community. In addition, these factors will be helpful in the projects that are undertaken for the enhancement of the quality of life of middle-income group. If it is a landscape project: the client (Government/ Non-Government Organization/ Private firm) who is handling the project can take an idea about the living condition of the community and what need to be improved within the canal waterfront. This research is only focusing on the Middle-Income group and the set of indicators were chosen in the perspective of Landscape Architectural aspects.

\subsection{PROPOSED LIVEABILITY INDEX FOR GREATER COLOMBO CANAL WATERFRONTS}

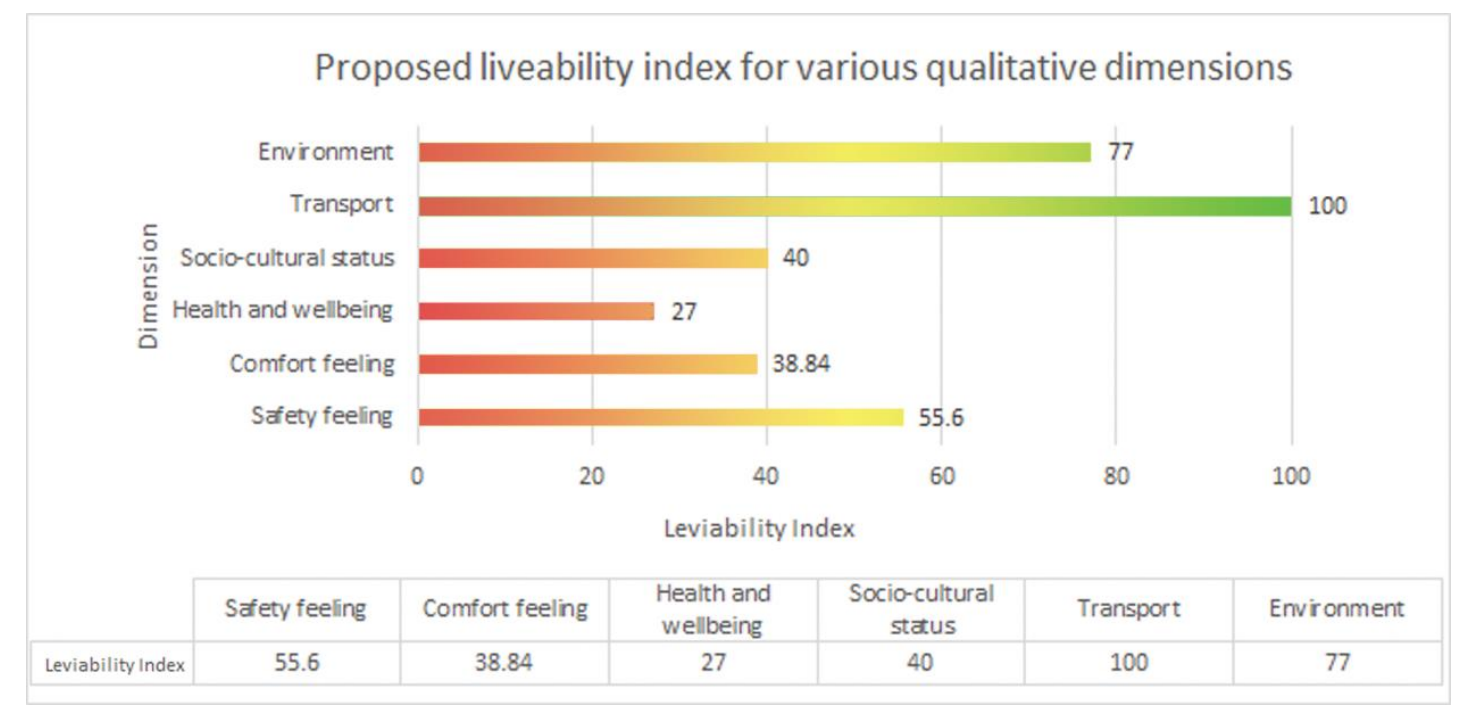

Figure 2: Proposed liveability index for various qualitative dimensions (Source: Author)

Summary of the liveability index along Greater Colombo canal waterfronts, related to middleincome groups' perception can be demonstrate as above. The above figure only represents the human perceptions on six different dimensions. It is clear that the community is happy in the dimension of transport. The outcome was taken from the participants' respondent on implementing water transportation. Two main reasons behind the above preference was the perceptions of human on reduction of the traffic congestion within the Greater Colombo region and the perception on the increment of tourism. The next highest rating is for the environmental dimension. Most of the community is happy with the existing environmental condition. According to their perceptions, it is still at a good level. However, the government have to care more toward the natural environment along urban canal waterfronts since it 
would be degrading with the lack of attention. Otherwise, it will be a canal of plastic and polythene. Comfort level and the socio-cultural status are at a moderate level. Therefore, the government must address these factors more, if any project is to be carried out along urban canal waterfronts or if any action is to be taken for enhancing their quality of life. The Lowest rating is for the sanitation facilities they have. Most of the respondents stated that the reason behind it is the low level of sanitation along urban canal waterfronts. Overall liveability index along urban canal waterfronts in Greater Colombo region can be presented as follows. It was formulated by the calculation of the mean value from both quantitative and qualitative indices.

\section{Proposed liveability index for urban canal waterfronts in Greater Colombo region}

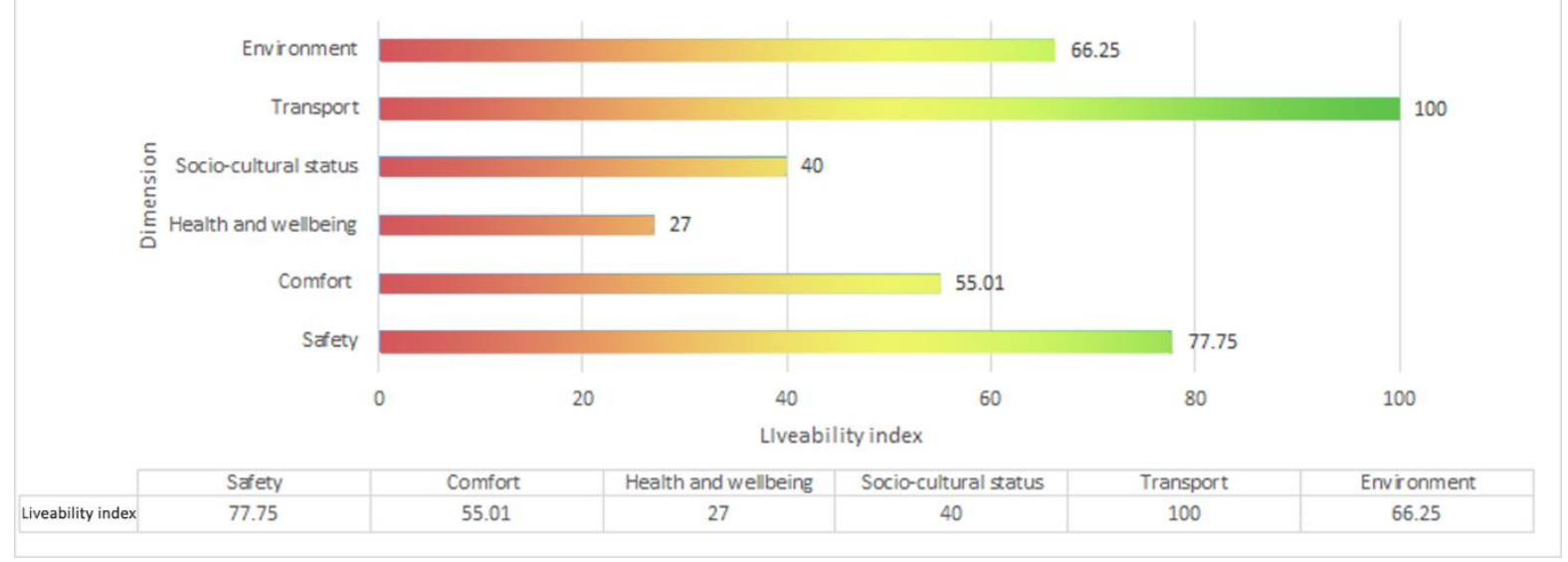

Figure 3: Proposed liveability index for urban canal waterfronts in Greater Colombo region (Source: Author)

This is the main outcome of the study. Three dimensions were varied after the combination of both quantitative and qualitative indices. Reason for the variation of rating value is that the statistical data is more accurate than human perceptions and the perceptions are coming through a procedure of a combination of suspicious thinking and their likeliness. Therefore, a best outcome can be taken by the combining of both these two factors. The rating of safety dimension has increased by 22 units due to the low level of crime rate (statistical data). Rating on the environmental dimension has decreased a bit due to the ratings in relation to statistical data are lower in Greater Colombo region according to the world standards and when comparing the situations of rural context in Sri Lanka. Only the qualitative data ratings were taken from the three dimensions (health and wellbeing, transport and the socio-cultural situation) for the calculation of final liveability index.

The above findings will be helpful in; the preparation of rules and regulations, to have an idea on the liveability status of middle-income group or for the implementation of related projects along urban canal waterfronts in the Greater Colombo region.

\section{Conclusion}

The urban canal network of Greater Colombo region is in a danger position compared to all the other canals in Sri Lanka due to the lack of attention to the quality of life of surrounding community and the waterfronts. According to the results obtained, there is an unsafe condition in front of individuals' shelter according to the user perceptions. Safety dimension is the second highest rated dimension according to the proposed liveability index for urban canal waterfronts in the Greater Colombo region. When the statistical data were combined with analytical data, the safety dimension have shifted to a range in between good and moderate. It is due to the low crime rate in Colombo region. This value has affected to the increment of safety index. Comfortability rating is in the range of moderate and good, because the environment is somewhat calm compared to the urbanized regions. The health and wellbeing rating is the lowest among all. Middle-income community have stated that the overall sanitation condition is getting worse with the low level of sanitation of lower-income group. The government can address these lower rated dimensions when they are going to implement new development projects or community-based development projects along urban canal waterfronts in the Greater Colombo region. 
Overall, the middle-income community is satisfied with the environment that they live. The value of such water-based ecosystems can be identified with these kinds of studies. These canals and waterfronts must be preserved and conserved for future generations without letting them be degraded or spoiled. Otherwise, these canals will be the places for garbage dumping and will be rivers of plastics and polythene with the lack of attention to the canals and the quality of life of people along waterfronts.

\section{References}

Aalfs, M., Arnold, J., Bollinger, D., Breslow, S., Cannon, S., Carroll, N., ... Tuttle, C. (1998). Sustainable Seattle: indicators of sustainable community. Seattle.

Administration, N. O. (2018). What is a canal? Retrieved from National Ocean Service: https://www.oceanservice.noaa.gov/facts/canal.html

Anupoju, S. (n.d.). Classification of canals based on different factors. Retrieved from The Constructor: https://www.theconstructor.org/waterresources/classification-canals-different-factors/32294/

Balsas, C. J. (2004). Measuring the livability of an urban centre: An exploratory study of key performance indicators. Planning Practice and Research Practice \& Research, 1, 101-110. doi:10.1080/0269745042000246603

Bandara, A. M. (1993). Land use planning under minor irrigation schemes in the dry zone of Sri Lanka. University of Moratuwa.

Canal network to be used for passenger transport. (2016). Retrieved from Colombo Gazette: https://colombogazette.com/2016/02/11/canal-network-to-be-usedfor-passenger-transport/

Carmichael, A., Gleason, D., Lehrmitt , R., \& Luppino , C. (2007). City of Westminster livability index. London: Worcester Polytechnic Institute.

Cummins, R. A., Eckersley, R., Pallant, J., van Vugt, J., \& Misajon, R. (2003). Developing a national index of subjective wellbeing: The Australian unity wellbeing index. Social Indicators Research, 64, 159-190. doi:10.1023/A:1024704320683

Encyclopaedia Britannica (15th ed.). (2010). US: Encyclopaedia Britannica, Inc.

Fatemi, N., \& Islam, N. (2014). Learning from precedents: emerging urban planning practices towards livable communities in Dhaka. ICCPP. University of Moratuwa.

Giovinazzi, O., \& Moretti, M. (2010). Port cities and urban waterfront: transformations and opportunities. Journal of Land Use. Mobility and Environment, 2. doi:10.6092/19709870/123

Herath, S. (1996). Utilizing canal banks as urban waterfronts to enhance the built environment in Colombo city. University of Moratuwa.

Heylen, K. (2006). Liveability in social housing: three case-studies in Flanders. Housing in an expanding Europe: Theory, policy, participation and implementation. Retrieved from

http://web.usm.my/jcdc/input/JCDC\%20Vol\%2015\%281\%29/JCDC\%20Vol \%2015\%20\%281\%29\%20ART\%204\%20\%2867-

Hortulanus, E. P. (2000). The development of urban neighbourhoods and the benefit of indication systems. Social Indicators Research, 50(2), 209-224.

Lalor, J. J., Wolowski, L., \& Roscher, W. (2015). Principles of political economy (Vol. 1). Sagwan Press. Lane, F. C. (1973). Venice: a maritime republic. The Johns Hopkins University Press.

Lau, J. L., \& Hashim, A. H. (2010). Liveability dimensions and attributes: Their relative importance in the eyes of neighbourhood residents. Journal of Construction in Developing Countries, 15(1).

Lyndhurst, B. (2004). Livability \& sustainable development: bad habits \& hard choices. UK: ODPM. New country classifications by income level: 2019-2020. (2020). Retrieved from World Bank Blogs: https://blogs.worldbank.org

Oestigaard, T. (2005). Water and world religions. An introduction. Bergen: SFU \& SMR.

Oestigaard, T., \& Firew, G. A. (2013). The source of the Blue Nile: water rituals and traditions in the Lake Tana region (Unabridged ed.). Cambridge Scholars Publishing.

Perera, R. (2003). Problems and prospects of utilizing canal banks to enhance the built environment in Colombo. Builtenvironment Sri Lanka, 3(2), 75-81. doi:10.4038/besl.v3i2.7644

Quality of life. (2020). Retrieved from NUMBEO: https://www.numbeo.com/qualityof-life/82

Shamsuddin, S., Hassan, R., \& Bilyamin, S. F. (2012). Walkable environment in increasing the liveability of a city. Social and Behavioral Sciences, 50, 167- 178. doi: 10.1016/j.sbspro.2012.08.025

Sharma, S. (2003). Water in Hinduism: continuities and disjunctures between scriptural canons and local traditions in Nepal. Water Nepal, 10(1). doi:10.3126/wn.v10i1.103

Stevenson, A., \& Lindberg, C. A. (Eds.). (2010). New Oxford American Dictionary (3rd ed.). Oxford University Press. doi:10.1093/acref/9780195392883.001.0001

The global liveability index. (2019). Retrieved from The Economist: Intelligence Unit: 
https://www.eiu.com/topic/liveability\#: :text=The\%20Global\%20Liveability\%20Index,lifestyle $\% 20$ in $\% 2$ 0140\%20cities\%20worldwide.

Wheeler, S. M. (2001). Livable Communities: creating safe and livable neighborhoods, towns, and regions in California. UC Berkley. Retrieved from https://escholarship.org/uc/item/8xf2d6jg 